\title{
Phase Transition and Liquid Crystalline Structures of Side-Chain Liquid-Crystalline Polysiloxanes Containing Acetoyl Group as a Mesogenic Terminal Substituent
}

\author{
Koichiro Yonetake, ${ }^{\dagger}$ Junichi Soga, and Toru Masuko \\ Faculty of Engineering, Yamagata University, \\ Jonan 4, Yonezawa, Yamagata, 992 Japan
}

(Received November 8, 1996)

\begin{abstract}
Polysiloxanes containing acetoy group as a mesogenic terminal substituent were synthesized and the effects of acetoyl group on liquid crystalline properties and structures were investigated. The poly[ $[\omega-\{4-(4-($ acetoyl)phenoxy carbonyl)phenoxy\}\}alkyl methyl siloxanes] with different spacer lengths indicate smectic phases in the temperature range between glass transition $\left(T_{\mathrm{g}}\right)$ and isotropic phase transition $\left(T_{\mathrm{i}}\right)$. Smectic $\mathrm{A}\left(\mathrm{S}_{\mathrm{A}}\right)$ phase was observed in each polymer, and additional smectic phase appeared under the $S_{A}$ phase as spacer lengths increased. The higher ordered smectic phase could be assigned to smectic E-like phase from the X-ray scattering results. The $T_{\mathrm{i}}$ 's, enthalpy and entropy changes of the polymers exhibited clearly odd even effects.

KEY WORDS Side Chain Liquid Crystalline Polymer / Polysiloxane / Acetoy Group / Smectic A / Smectic E / Odd-Even Effect /
\end{abstract}

A lot of side-chain liquid-crystalline polymers (SCLCP) have been synthesized in recent years, since many variations on the structures of SCLCPs are possible. The variety of the chemical structures give complicated liquid crystalline properties. The phase transition behaviors, liquid crystalline textures, and stability of mesophase of the SCLCPs depend on the chemical structures of mesogenic groups, length of flexible spacer group, and mesogenic terminal groups. The influence of these factors on the liquid crystalline property of SCLCPs have been investigated by many researchers. ${ }^{1-5}$

Generally the chain length, chirality and polarity of the terminal groups profoundly influence on the formation of liquid crystalline phase. ${ }^{2-4}$ When the polarity of mesogenic terminal groups is noted, the less polar terminal substituents (alkyl, alkoxy) tended to exhibit nematic phases. ${ }^{4,6-10}$ Additionally, the appearance of the mesophase depended on the spacer length. The longer spacers encouraged additional higher ordered mesophases even in above SCLCPs with less mesogenic terminal groups; the longer spacers induced smectic phases. ${ }^{4,7,8}$ On the other hand, the mesogens containing polar terminal groups like cyano and nitro groups were smectogenic, and the clearing temperatures increased with the terminal group polarity. $4,9-16$

In this article, we synthesized side-chain liquidcrystalline polysiloxanes containing acetoyl group as a mesogenic terminal substituent; i.e., introduction of keton group into the terminal substituent. Very little has published concerning SCLCPs with acetoyl terminal group. It is interesting to explore the influence of such a simple acetoyl group on the liquid crystalline nature, as compared with above terminal groups. We synthesized poly $[\{\omega-\{4-(4-($ acetoyl)phenoxy carbonyl)phenoxy $\}\}-$ alkyl methyl siloxanes] with different flexible spacer lengths, and investigated the liquid crystalline natures and the effects of acetoyl group on their liquid crystalline

\footnotetext{
† To whom all correspondence should be addressed.
}

properties and structures using thermal analysis, optical microscope, and X-ray diffraction method.

\section{EXPERIMENTAL}

\section{Materials}

Side-chain liquid-crystalline polysiloxane having mesogenic 4-acetoylphenyl 4-( $\omega$-alkenyloxy)benzoate pendant were prepared. The poly[ $\{\omega-\{4-(4-($ acetoyl) phenoxy carbonyl)phenoxy\}\}alkyl methyl siloxane] and mesogenic compound were coded as PAMS- $n$ and APB- $n$, respectively, where " $n$ " denotes the number of carbon in alkyl chain. The preparation and characterization were described in the Appendix section.

\section{Infrared, NMR, and Thermal Analysis}

The infrared spectra were recorded on a Hitachi I-5020 FT-IR spectrometer, and the NMR spectra on a JEOL EX $270(270 \mathrm{MHz})$ instrument. Thermal analyses were performed on a Seiko SSC 5000 thermal analyzer at a heating rate $10^{\circ} \mathrm{C} \mathrm{min}^{-1}$ for thermogravimetric analysis (TGA). Differential scanning calorimetry (DSC) of the samples was performed by use of a DSC 200 (Seiko I \& E Ltd.) under an $\mathrm{N}_{2}$ purge; heating and cooling rates were $20^{\circ} \mathrm{C} \mathrm{min}^{-1}$ and $10^{\circ} \mathrm{C} \mathrm{min}^{-1}$, respectively.

\section{Polarized Optical Microscopy}

Changes in optical textures of the samples during heating and cooling processes were examined using the polarizing optical microscope (POM) equipped with a hot stage (Linkam Co., TH-600RMS) under an $\mathrm{N}_{2}$ purge.

\section{X-Ray Scattering Measurements}

X-Ray scattering (XRS) experiments were carried out by a RAD-rA diffractometer (Rigaku Denki Co., Ltd.) equipped with a heating device of which temperature accuracy was $\pm 0.2^{\circ} \mathrm{C}$. Nickel-filtered $\mathrm{Cu}-K_{\alpha}$ radiation was employed. Changes in the X-ray scattering traces during heating and cooling processes were recorded by a scintillation counter system with a $1.0 \mathrm{~mm}$ diameter 
pinhole collimator and $1 \times 1^{\circ}$ receiving slit. The diffractometry was performed in transmission. XRS traces were obtained by a step-scanning method: The step width and fixed time were programmed for steps of $0.05^{\circ}$ every $4 \mathrm{~s}$. The XRS photographs were taken by a flat Laue camera with a $0.5 \mathrm{~mm}$-diameter pinhole collimator.

\section{RESULTS AND DISCUSSION}

\section{Synthesis of Mesogenic Compounds and Liquid Crystalline} Polysiloxanes

The mosogenic compound APB- $n$ was prepared by the condensation of 4-( $\omega$-alkenyloxy)benzoic acid with 4 '-hydroxyacetophenone in $31-70 \%$ yield as shown in Scheme 1.

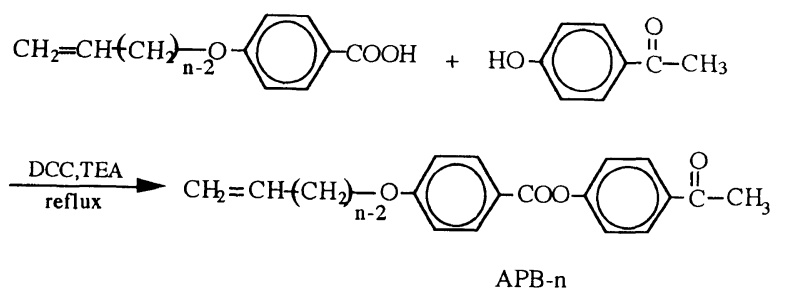

Scheme 1.

Side-chain liquid-crystalline polysiloxane PAMS- $n$ by the hydrosilylation reaction between poly(hydrogenmethylsiloxane)s and APB- $n$ in the presence of platinum catalyst as shown in Scheme 2.

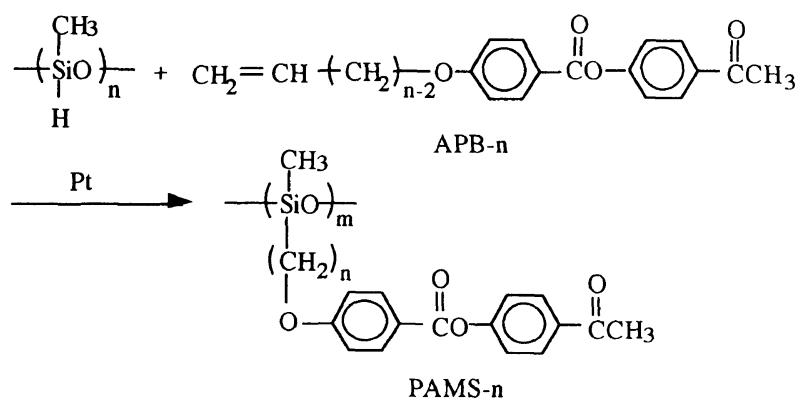

Scheme 2.

The extent of the reaction was followed by the disappearance of absorption of silyl hydride at $2160 \mathrm{~cm}^{-1}$ in the IR spectrum. Polymers were purified by repeated precipitation from methylene chloride solution with excess methanol, and then were isolated by filtration. PAMS- $n$ were defined as corresponding polysiloxanes containing 4-acetoylphenyl 4-( $\omega$-alkenyloxy)benzoate group as a side chain mesogen unit, by infrared spectroscopy and ${ }^{1} \mathrm{H}$ NMR analysis.

\section{Thermal Properties and Phase Transitions of Mesogenic Compounds $A P B-n$}

Figure 1 compares DSC traces of second heating and cooling processes for APB-n. Both DSC traces of APB-3 and APB-4 exhibited single endothermic and single exothermic peaks in the heating and cooling processes, respectively. Many sharp reflections which could be assigned to crystal phase were shown in their X-ray diffraction patterns obtained below the endothermic and exothermic peaks. A dark field was observed under the POM with crossed polarizers above both peaks. Con-

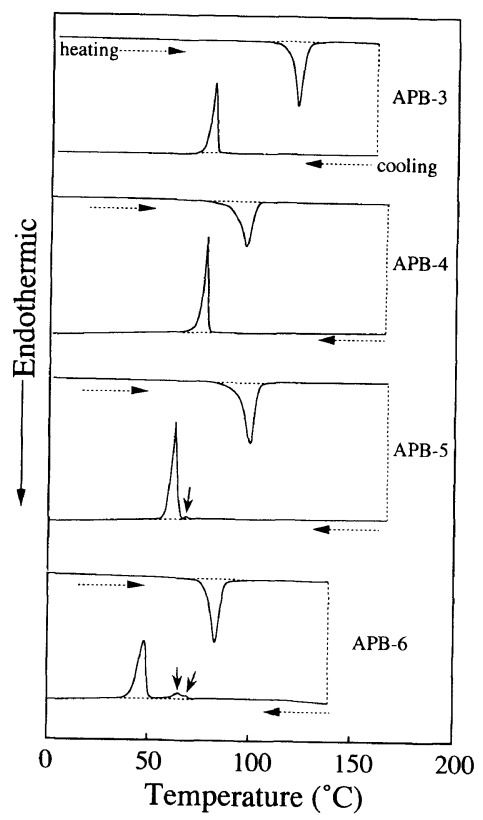

Figure 1. DSC traces of 2nd heating and cooling processes for mesogenic compound APB- $n$; 4-acetoylphenyl 4-( $\omega$-alkenyloxy)benzoate.

sequently, the phase transitions of APB-3 and APB-4 were assigned to isotropic phase transition $\left(T_{\mathrm{i}}\right)$.

APB-5 and APB-6 also showed one endothermic peak in the heating process, but two or three exothermic peaks could be observed in the cooling process; peaks which appeared at the higher temperature side of the large peak were very small as indicated by arrows in Figure 1. Change in optical textures during each cooling process was observed under the POM to assign these exothermic peaks. Typical schlieren texture corresponding to nematic phase appeared between the two exothermic peaks (62.6 and $68.8^{\circ} \mathrm{C}$ ) in APB-5. In the case of APB-6, on the other hand, focal-conic fan texture was observed between the two exothermic peaks $\left(47.8\right.$ and $\left.65.2^{\circ} \mathrm{C}\right)$, as shown in Figure 2. Additionally, nematic texture appeared in the narrow temperature range between the small endothermic peak and small shoulder $\left(65.2\right.$ and $\left.68.4^{\circ} \mathrm{C}\right)$.

The phase transitions of APB- $n$ were summarized in Table I. APB-5 exhibited nematic liquid crystailine phase, and APB-6 smectic and nematic liquid crystalline phases on cooling. Thus, APB-5 and APB- 6 with longer alkyl chains gave monotropic liquid crystalline properties. The phase transition temperatures are plotted against length of alkyl chain $(n)$ in Figure 3. The temperatures of isotropic phase transition decreased with increasing $n$, indicating odd-even effect. The temperature range of liquid crystalline phase expanded with increasing $n$.

\section{Thermal Properties and Phase Transitions of Liquid Crystalline Polysiloxanes PAMS- $n$}

The DSC traces of PAMS- $n$ are illustrated in Figure 4 , which correspond to the second-heating processes. A remarked glass transition $\left(T_{\mathrm{g}}\right)$ was obtained on the DSC trace of each sample. $T_{\mathrm{g}}$ 's decreased with increasing $n$. This results in internal-plasticization effect of flexible spacers; i.e., increase in spacer length decouples the mobilities of backbones and mesogenic groups. Single endothermic peak was observed on the DSC traces of 


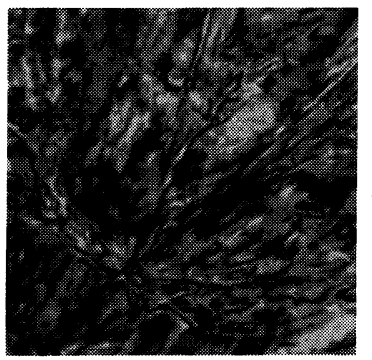

$40^{\circ} \mathrm{C}$

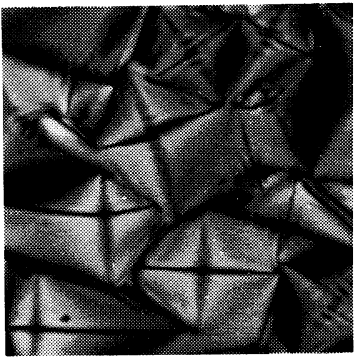

$59^{\circ} \mathrm{C}$

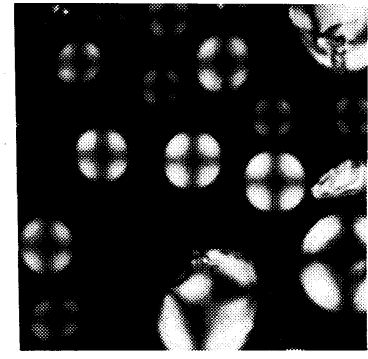

$67^{\circ} \mathrm{C}$

Figure 2. Optical textures of APB-6 during cooling process.

Table I. Phase transition temperatures of APB- $n^{\text {a }}$

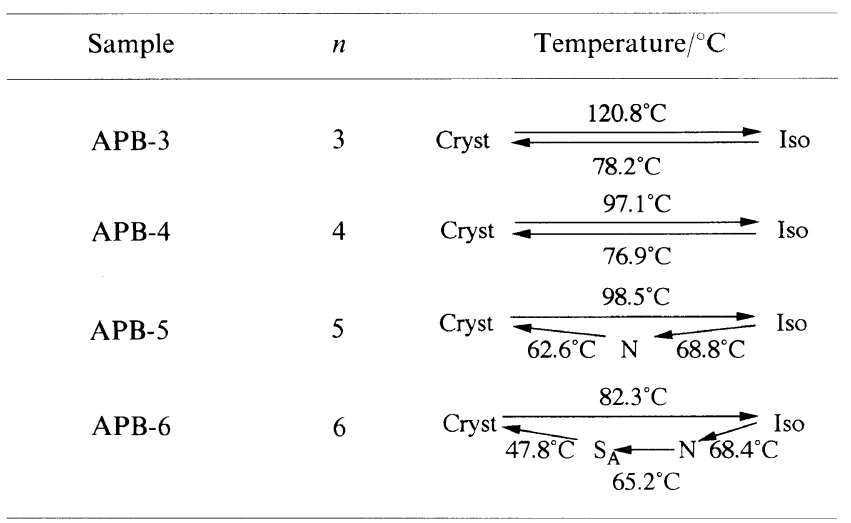

${ }^{a}$ Cryst, crystal; $\mathrm{S}_{\mathrm{E}}$-like, smectic E-like; $\mathrm{S}_{\mathrm{A}}$, smectic $\mathrm{A}$; Iso, isotropic melt.
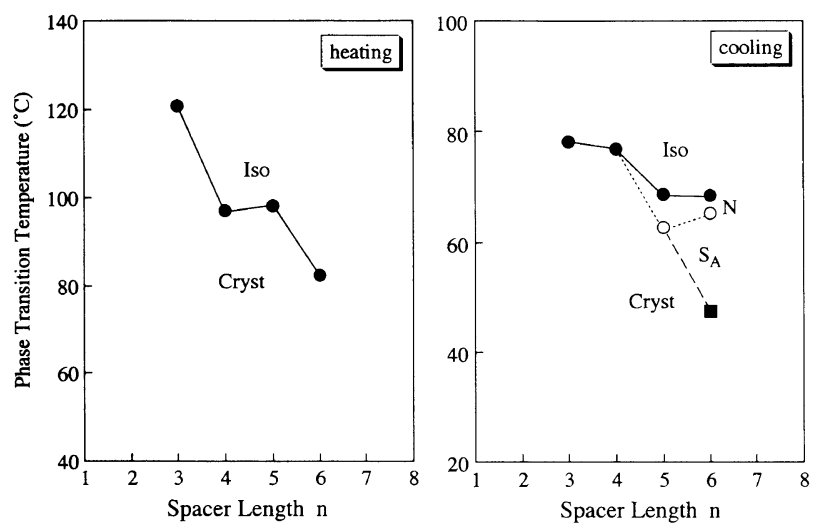

Figure 3. Change in phase transition temperatures of APB- $n$ versus spacer length $(n)$ during heating and cooling processes. Iso, isotropic melt; $\mathrm{N}$, nematic; $\mathrm{S}_{\mathrm{A}}$, smectic A; Cryst, crystal.

PAMS-3 and PAMS-4; in contrast, two endothermic peaks were observed in PAMS-5 and PAMS-6. Under POM, a dark field appeared above the endothermic peak of PAMS-3 and PAMS-4, and above the higher endothermic peak of PAMS-5 and PAMS-6. After cooling from the isotropic melt, well-defined focal-conic fan and battonet textures formed in each sample. Figure 5 shows the optical texture of PAMS-6. Thus, these endothermic peak were assigned to the phase transition from smectic to isotropic phases. In PAMS-5 and PAMS-6, the optical texture almost remain unchanged below the lower endothermic peak, so that the lower endothermic peaks could not be assigned using POM.

The XRS patterns of oriented samples for PAMS-3 and PAMS-4 indicated a diffuse meridional scattering at

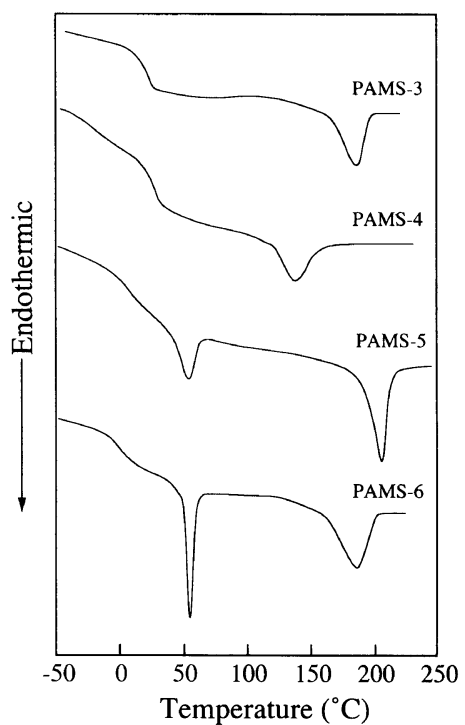

Figure 4. DSC thermograms of 2nd-heating process for PAMS- $n$.

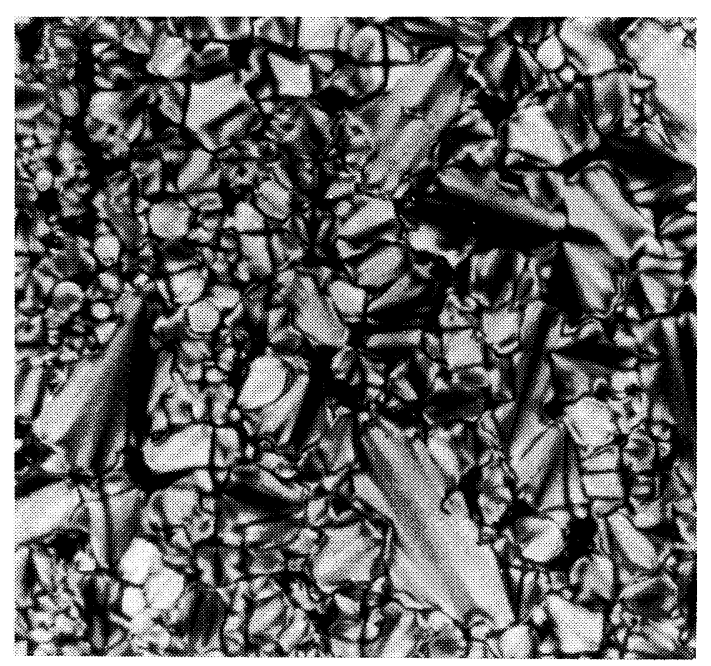

Figure 5. Optical textures of PAMS-6 taken at room temperature.

a wide-angle area, and periodic equatorial arcs at a small-angle area, characteristic of smectic $A\left(S_{A}\right)$ phase, as shown in Figure 6. They were taken at room temperature. On the other hand, those of PAMS-5 and PAMS-6 taken at room temperature indicated some comparatively sharp meridional reflections at the wideangle area, suggesting existence of higher ordered smectic phase. Above their lower endothermic peaks, the sharp reflections at the wide-angle area disappeared and changed into a diffuse scattering, as shown in Figure 6. 


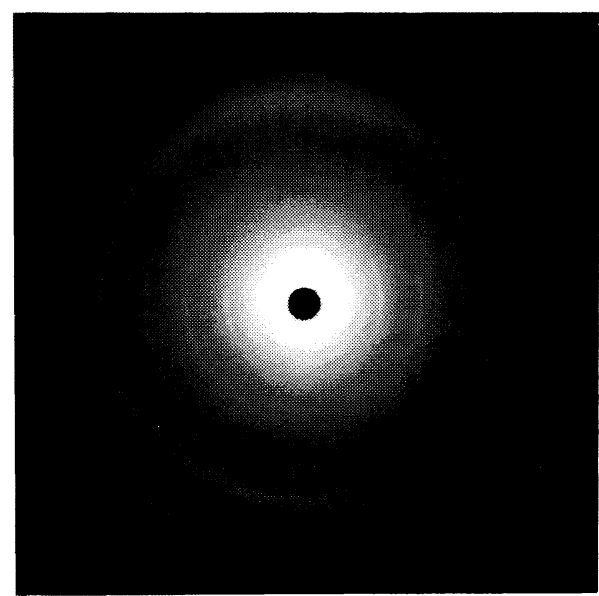

PAMS-3 (RT)

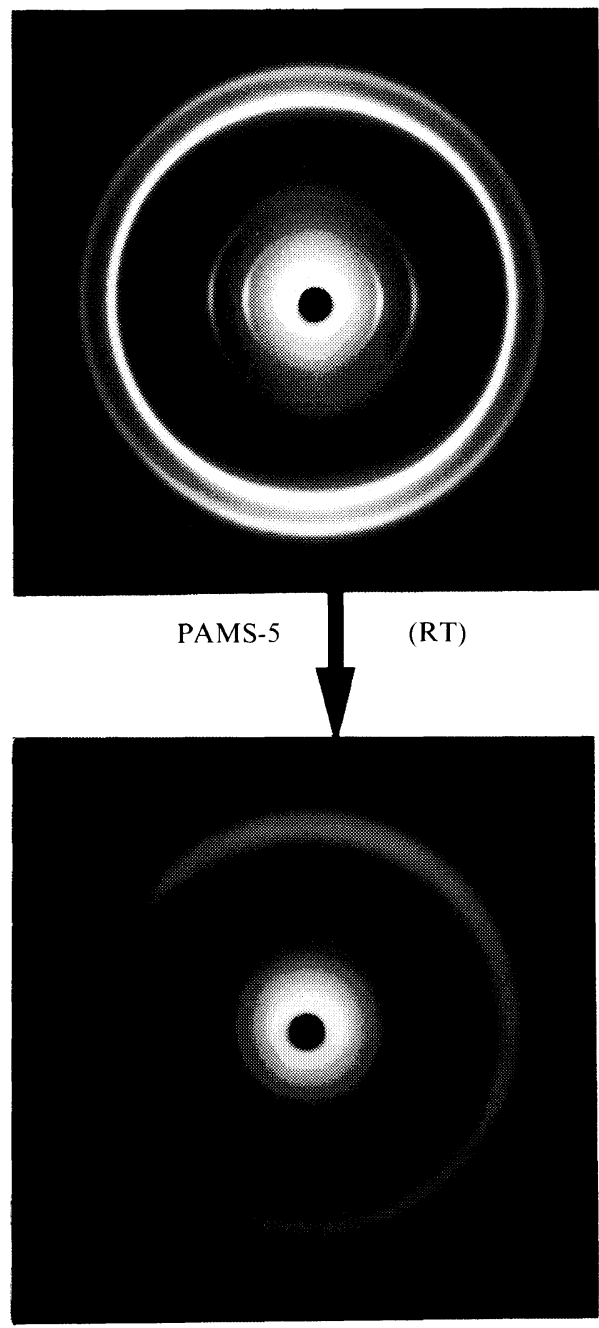

PAMS-5 $\left(75^{\circ} \mathrm{C}\right)$
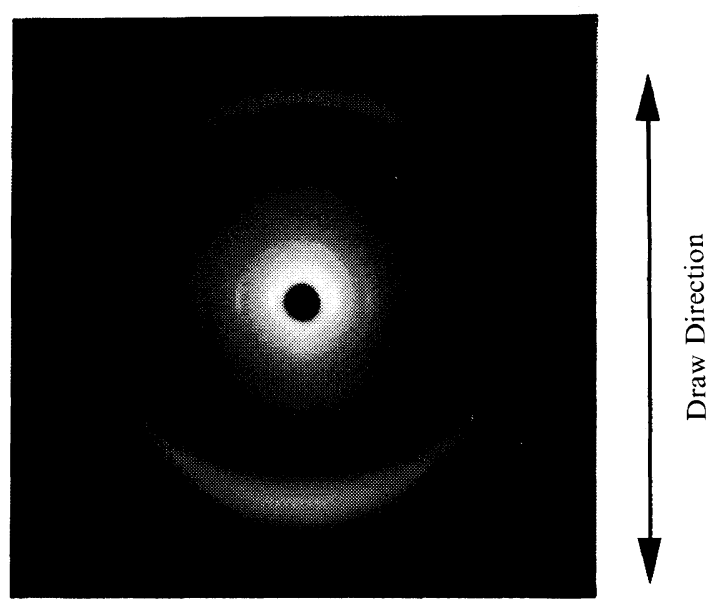

PAMS-4 (RT)
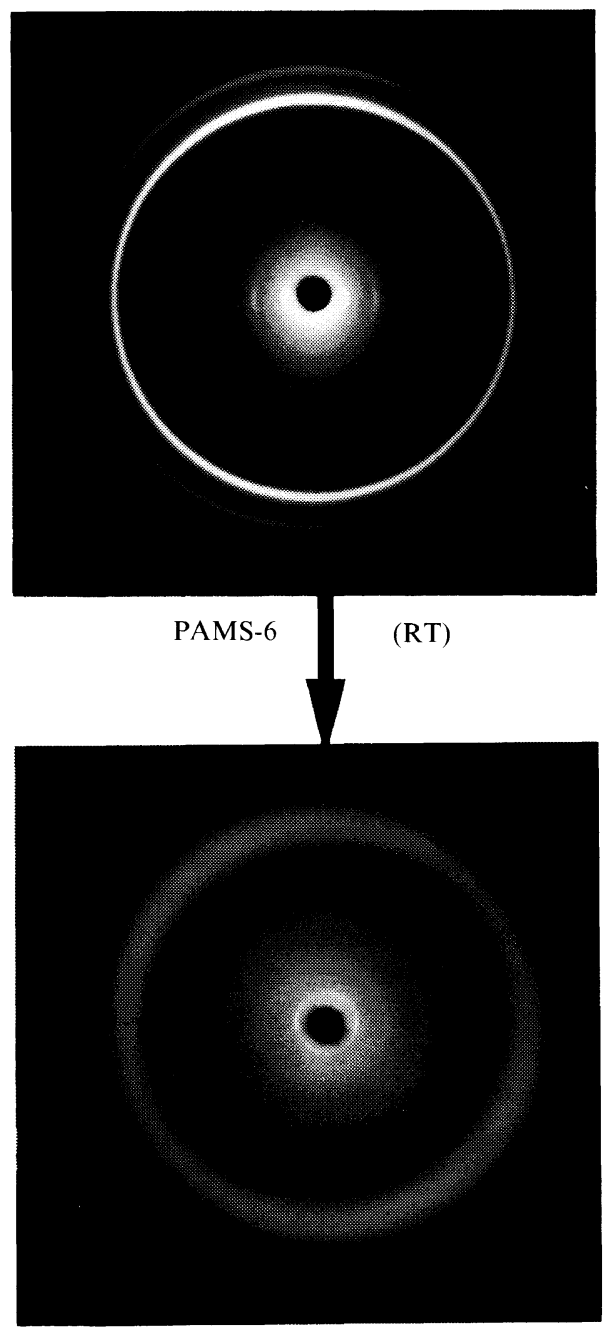

PAMS-6 $\quad\left(75^{\circ} \mathrm{C}\right)$

Figure 6. XRD photographs of PAMS- $n$ taken at room temperature $(R T)$ and $75^{\circ} \mathrm{C}$.

The XRS patterns taken at $75^{\circ} \mathrm{C}$ were similar to those of PAMS-3 and PAMS-4; thus, PAMS-5 and PAMS-6 also exhibited $S_{A}$ phase at the higher temperature range.

Change in the XRS traces of PAMS-5 and PAMS-6 during the heating and cooling processes are illustrated in Figures 7 and 8, respectively. Figure 7 shows change in the XRS traces at the wide-angle area $\left(15-35^{\circ}\right)$, where the sharp reflections disappeared above $60^{\circ} \mathrm{C}$ in both samples. On the other hand, the reflections observed at the small-angle area $\left(2-15^{\circ}\right)$ remained unchanged in the range between 30 and $90^{\circ} \mathrm{C}$, as illustrated in Figure 8; i.e., smectic layer structure kept in the temperature range. 

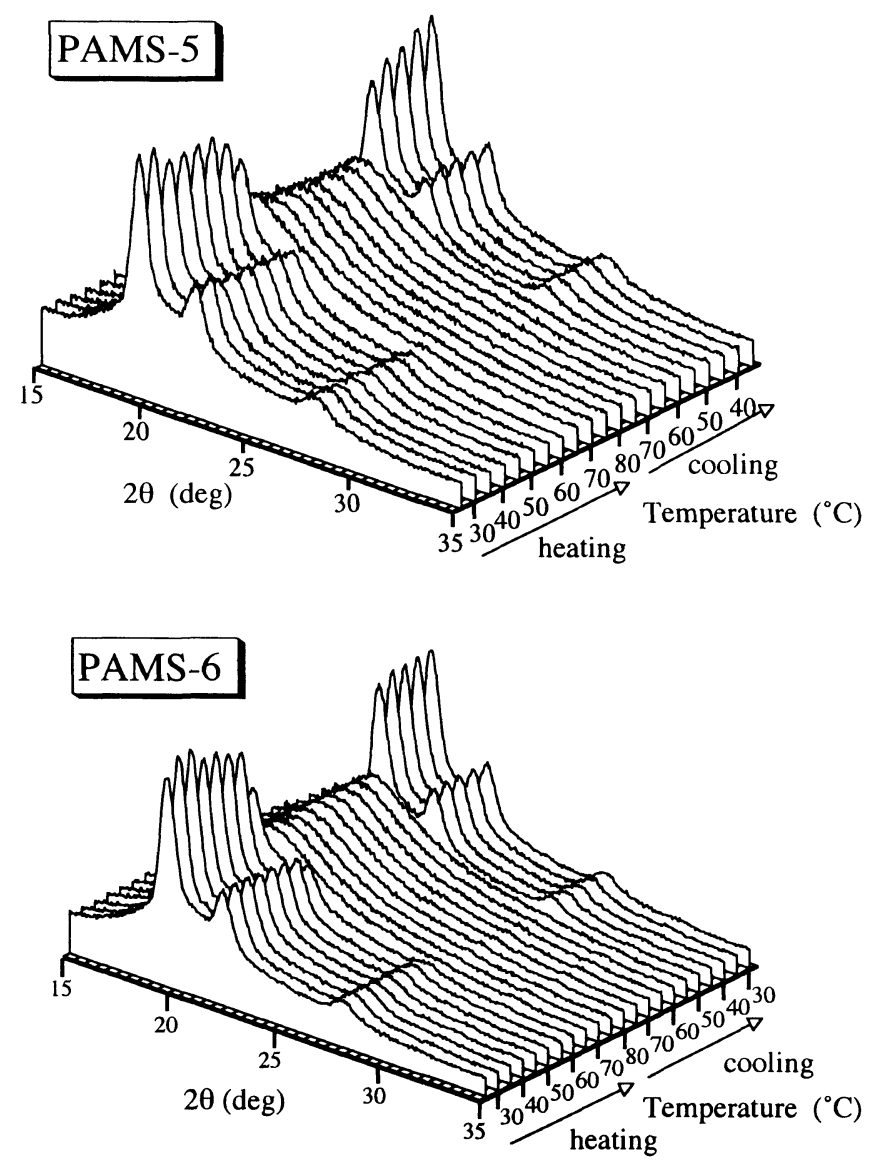

Figure 7. Change in XRD traces $\left(2 \theta=15-35^{\circ}\right)$ of PAMS-5 and PAMS-6 during heating and cooling processes.

These findings suggest that the phase transition from a higher ordered smectic phase to $S_{A}$ occurred at approximately $60^{\circ} \mathrm{C}$. These XRS results were consistent with the DSC results described above.

Some sharp reflections were observed in the wide-angle XRS traces as shown in Figure 7. In the case of PAMS-5, when the two sharp reflections obtained at $2 \theta=19.8$ and 22.6 were assumed to (110) and (200) reflections of an orthorhombic packing mode, respectively, the lattice parameters $a$ and $b$ were estimated; $a=0.786 \mathrm{~nm}$ and $b=0.545 \mathrm{~nm}$. Using the lattice parameters, other reflections could be indexed as summarized in Table II. All of observed $d$ spacings were consistent with the calculated $d$ spacings within an experimental error. A similar result was obtained in PAMS-6, as shown in Table II. Accordingly the mesogenic side chains were packed by the orthorhombic packing mode within the smectic layers. The smectic structure resembles smectic $E\left(S_{E}\right)$ for monomeric liquid crystals. Only $(h k 0)$ reflections can be observed, as shown in Table II. This implies that the structure is not considered to be of three dimensional order. One reason for this is that the flexible backbones are forced to be confined between the smectic layers. Their structures are similar to that of poly[6-[4-(4methoxyphenyl)phenoxy]hexylmethacrylate]. ${ }^{17}$ Thus, PAMS-5 and PAMS-6 exhibited $S_{E}$-like phase in the lower temperature range. Additional smectic phases appeared as spacer lengths increased. Such a behavior was reported in liquid crystalline polysiloxanes containing terminal cyano group. ${ }^{11,16}$ Though the structure of
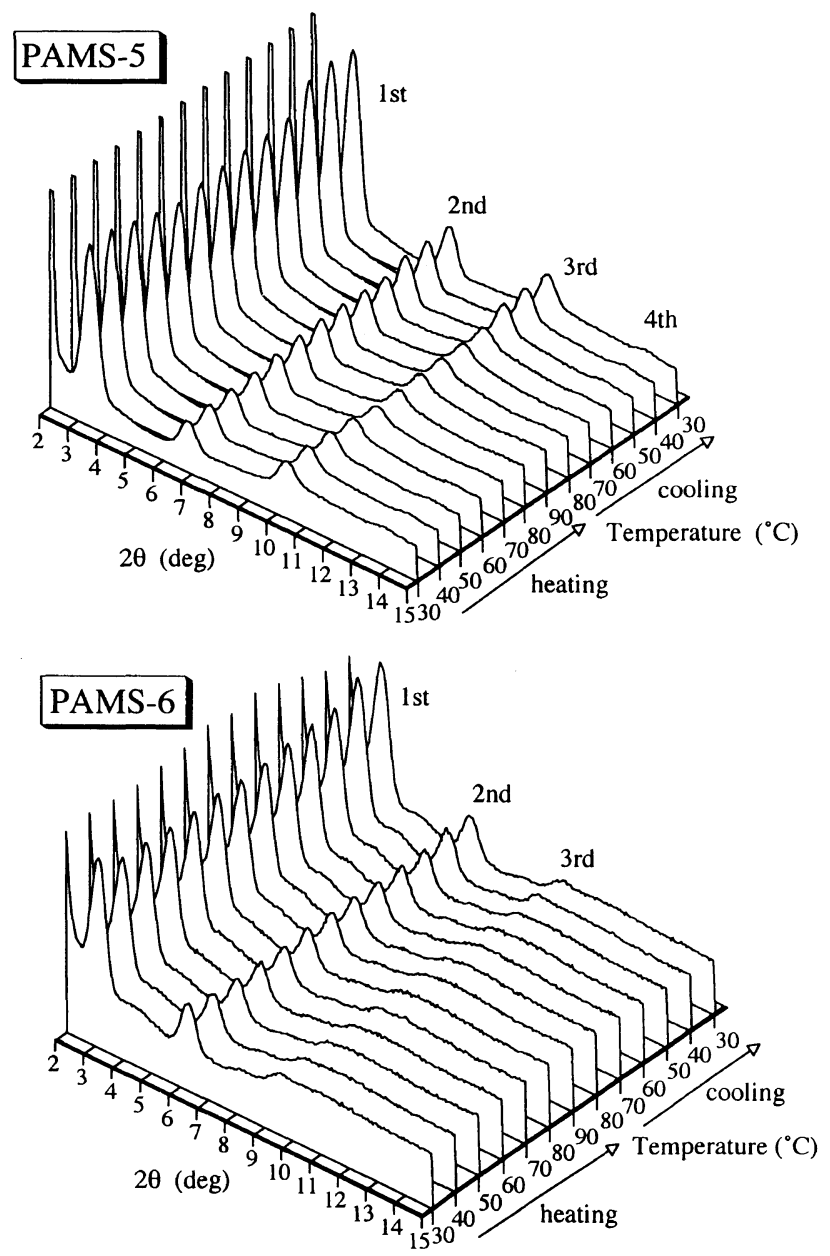

Figure 8. Change in XRD traces $\left(2 \theta=2-15^{\circ}\right)$ of PAMS-5 and PAMS-6 during heating and cooling processes.

Table II. Phase transition temperatures of PAMS- $n$ with various spacer lengths ${ }^{\mathrm{a}}$

\begin{tabular}{|c|c|c|c|c|c|}
\hline Sample & $n$ & \multicolumn{4}{|c|}{ Phase transition temperatures $/{ }^{\circ} \mathrm{C}$} \\
\hline PAMS-3 & 3 & g & $\stackrel{14.2}{\longrightarrow} \mathrm{SA}$ & $\underset{175.5}{\stackrel{187.8}{\rightleftharpoons}}$ I & \\
\hline PAMS-4 & 4 & g & $\stackrel{13.5}{\rightleftharpoons} \mathrm{SA}_{\mathrm{A}}$ & 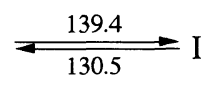 & \\
\hline PAMS-5 & 5 & $\mathrm{~g}=$ & $\stackrel{-1.4}{\longrightarrow}$ SE-like & $\underset{38.5}{\stackrel{54.8}{\rightleftharpoons}} \mathrm{SA}_{\mathrm{A}}$ & $\underset{190.9}{\stackrel{205.7}{\longrightarrow}} \mathrm{I}$ \\
\hline PAMS-6 & 6 & $g \neq$ & $\stackrel{-8.9}{\longrightarrow}$ SE-like & $\underset{37.9}{\stackrel{55.4}{\rightleftharpoons}} \mathrm{SA} \rightleftharpoons$ & $\underset{182.8}{\stackrel{188.3}{\longrightarrow}} \mathrm{I}$ \\
\hline
\end{tabular}

a g, glass; $\mathrm{S}_{\mathrm{E}}$-like, smectic E-like; $\mathrm{S}_{\mathrm{A}}$, smectic $\mathrm{A}$; Iso, isotropic melt.

the additional phase for the cyano-substitued polysiloxanes was similar crystalline ordering, ${ }^{11}$ the packing mode of the mesogenic side chains is considered to be hexatic; i.e., the phase was assigned to smectic $\mathrm{B}^{3}$ If a hexatic phase is formed at the lower temperature range in PAMS-5 and PAMS-6, the $d$ spacings $\left(d_{h k l}\right)$ of the $\mathrm{X}$-ray reflections observed at the wide-angle area exhibit the relationship of the hexagonal packing mode; $d_{110}$ : $d_{110}: d_{210}=1: 1 / \sqrt{3}: 1 / \sqrt{7}$. But, their $d$ spacings obtained did not show above relationship. Thus, the smectic phases are not assigned to hexatic smectic B. Consequently, the introduction of acetoyl terminal group induced a highly ordered smectic phase. The phase 
Table III. $d$-Spacing of PAMS-5 and PAMS-6

\begin{tabular}{ccccccc}
\hline \multicolumn{3}{c}{ PAMS-5 } & & \multicolumn{3}{c}{ PAMS-6 } \\
\cline { 1 - 3 } \cline { 5 - 7 }$h k l$ & $d_{\text {calcd }} / \mathrm{nm}^{\mathrm{a}}$ & $d_{\text {obsd }} / \mathrm{nm}$ & & $h k l$ & $d_{\text {calcd }} / \mathrm{nm}^{\mathrm{b}}$ & $d_{\text {obsd }} / \mathrm{nm}$ \\
\hline 110 & 0.448 & 0.448 & & 110 & 0.444 & 0.444 \\
200 & 0.393 & 0.393 & & 200 & 0.389 & 0.389 \\
210 & 0.319 & 0.317 & & 210 & 0.316 & 0.315 \\
120 & 0.258 & 0.256 & & 120 & 0.256 & 0.254 \\
310 & 0.236 & 0.237 & & 310 & 0.234 & 0.234 \\
220 & 0.224 & 0.224 & & 220 & 0.222 & 0.223 \\
\hline
\end{tabular}

a Orthorhombic: $a=0.786 \mathrm{~nm} ; b=0.545 \mathrm{~nm}$. ${ }^{\mathrm{b}}$ Orthorhombic: $a=$ $0.778 \mathrm{~nm} ; b=0.542 \mathrm{~nm}$.

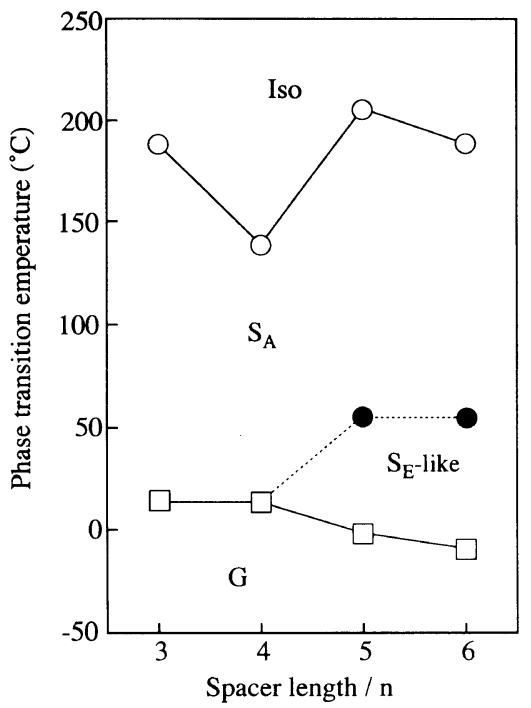

Figure 9. Changes in phase transition temperatures of PAMS- $n$ versus spacer length $n$. I, isotropic; $\mathrm{S}_{\mathrm{A}}$, smectic $\mathrm{A} ; \mathrm{S}_{\mathrm{E}}$-like, smectic E-like; $\mathrm{G}$, glass.

transitions of PAMS- $n$ were summarized in Table III.

Figure 9 shows the change in phase transition temperatures of PAMS- $n$ against the spacer length. The $T_{\mathrm{i}}$ exhibited clearly odd-even effect. Moreover, $S_{\mathrm{E}}$-like phase appeared with increasing $n$, and the $\mathrm{S}_{\mathrm{E}}$ range slightly expanded with increasing $n$. The enthalpy change $\left(\Delta H_{\mathrm{i}}\right)$ and entropy change $\left(\Delta S_{\mathrm{i}}\right)$ of the $\mathrm{S}_{\mathrm{E}}-$ like $/ \mathrm{S}_{\mathrm{A}}$ and $\mathrm{S}_{\mathrm{A}} /$ isotropic (I) phase transitions increased with spacer length, indicating the odd-even effect, as shown in Figures 10 and 11 , respectively. The $\Delta H_{\mathrm{i}}$ values are larger than other polysiloxane containing different terminal substituents. ${ }^{11}$ Strictly speaking, the comparison requires same degree of polymerization, since the clearing enthalpy might be dependent on the degree of polymerization of the polysiloxanes. The $T_{\mathrm{i}}$ and $\Delta H_{\mathrm{i}}$ of PAMS- 6 are larger than those of the polysiloxane containing cyanobipenyl mesogen, ${ }^{18,19}$ when they are compared at equal degree of polymerization of the polysiloxanes. As a result, acetoyl group encourages the stability of the smectic layer structure.

\section{Structures of Smectic Phase for PAMS- $n$}

The layer spacings of $\mathrm{S}_{\mathrm{A}}$ of PAMS-3 and PAMS-4 determined from the first-order X-ray reflection at the small-angle area gave $2.25 \mathrm{~nm}$ and $2.72 \mathrm{~nm}$, respectively, which were estimated from XRS photographs taken at room temperature. The lengths of the mesogenic side

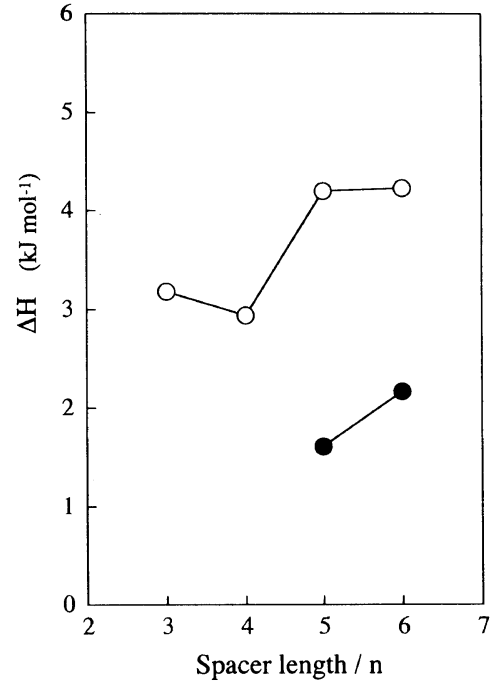

Figure 10. Change in $\Delta H$ of $\mathrm{S}_{\mathrm{E}}$-like/ $\mathrm{S}_{\mathrm{A}}$ and $\mathrm{S}_{\mathrm{A}}$ /isotropic (I) phase transitions for PAMS- $n$ versus spacer length $n$. $\bigcirc, \Delta H$ of $\mathrm{S}_{\mathrm{A}} / \mathbf{I}$ phase transition $\left(\Delta H_{\mathrm{i}}\right) ; \boldsymbol{\bullet}, \Delta H$ of $\mathrm{S}_{\mathrm{E}}$-like $/ \mathrm{S}_{\mathrm{A}}$ phase transition.

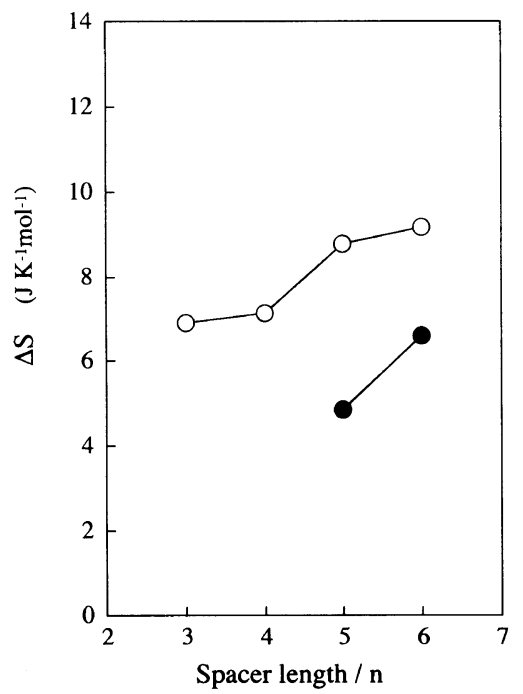

Figure 11. Change in $\Delta S$ of $\mathrm{S}_{\mathrm{E}}$-like/ $\mathrm{S}_{\mathrm{A}}$ and $\mathrm{S}_{\mathrm{A}} / \mathrm{I}$ phase transitions for PAMS- $n$ versus spacer length $n$. $\bigcirc, \Delta S$ of $\mathrm{S}_{\mathrm{A}} / \mathrm{I}$ phase transition $\left(\Delta S_{\mathrm{i}}\right)$; - $\Delta S$ of $\mathrm{S}_{\mathrm{E}}$-like $/ \mathrm{S}_{\mathrm{A}}$ phase transition.

chain for PAMS-3 and PAMS-4 were approximately $1.86 \mathrm{~nm}$ and $1.95 \mathrm{~nm}$, respectively. Accordingly the mesogenic side chain were overlapped each other within the smectic layer. In the cases of PAMS-5 and PAMS-6, their $S_{A}$ structures which appeared at high temperature range, were also considered to be the overlapping layer structure. The overlapping layer structures remained in their $S_{E}$-like phases after cooling from $S_{A}$.

Four periodic reflections associated with the $S_{A}$ layer structure could be observed in the small angle X-ray scattering patterns of PAMS-3, as shown in Figure 6. Third reflection appeared clearly in $S_{A}$ phase of PAMS-5. In the case of PAMS-4 and PAMS- 6 , on the other hand, only first and second reflections appeared in their $S_{A}$ phases, and a very week third reflection could be observed in the $S_{E}$ phase of PAMS-6. Thus, the order of the layer structure for PAMS- $n$ with odd $n$ is higher than those with even $n$. The result is connected with the thermal stability of PAMS- $n$ described in above section; namely, 
the odd-even effects of the $T_{\mathrm{i}}$ and $\Delta S_{\mathrm{i}}$ are due to the order of the layer structure. The order of the layer structure presumably results in the conformation of the side chain. It is hard to explain the effects of conformation on the layer structure in detail in terms of above limited experimental data.

\section{CONCLUSION}

The effects of acetoyl group on the liquid crystalline properties and the structures of liquid-crystalline polysiloxanes were investigated and following findings were obtained: Mesogenic compounds APB- $n$ exhibited only a crystal/isotropic phase transition with the heating process, whereas, APB- $n$ containing longer alkyl chains shows liquid crystalline phases; APB-5 exhibited nematic liquid crystalline phase, and APB-6 smectic and nematic liquid crystalline phases on cooling. Polysiloxanes containing the above mesogens, PAMS- $n$, indicate smectic phases in the temperature range between $T_{\mathrm{g}}$ and $T_{\mathrm{i}} . \mathrm{S}_{\mathrm{A}}$ phase was observed in each PAMS- $n$, and additional smectic phase appeared under the $\mathrm{S}_{\mathrm{A}}$ phase as the spacer length increased. The higher ordered smectic phase could be assigned to $\mathrm{S}_{\mathrm{E}}$-like phase from the X-ray scattering results; i.e., the mesogenic side chains were packed by orthorhombic packing mode within the layers. The $T_{\mathrm{i}}$ and $\Delta S_{\mathrm{i}}$ exhibited clearly odd-even effects. The odd-even effects were due to the order of their layer structures. $T_{\mathrm{i}}$ and $\Delta H_{\mathrm{i}}$ were higher than those of SCLCPs with other terminal groups. Thus, acetoyl group encouraged the order and the thermal stability of the smectic phase.

\section{APPENDIX}

\section{Preparation of Monomers and Polymers}

\section{Materials}

Toluene was successively washed with concentrated sulfuric acid, aqueous sodium hydroxide solution, and distilled water, dried over calcium chloride, and distilled. Polyhydrogenmethylsiloxane having $\bar{M}_{n}=3800, \bar{M}_{w}=$ 10500, $\bar{M}_{w} / \bar{M}_{n}=2.7$ was supplied by Chiso Co. 1-Bromo3-propene (B-3) and other reagents were obtained commercially and used as received.

\section{General Procedure for the Preparation of $\omega$-Bromoalkene $B-n(n=4-6)$}

To stirred $\omega$-bromoalkene $(103 \mathrm{mmol})$ at $200^{\circ} \mathrm{C}$ (oil bath temperature) was added hexamethylphosphoric triamide $(12 \mathrm{~mL})$ at a rate of about one drop per second. The temperature was then raised to $250^{\circ} \mathrm{C}$ for $5 \mathrm{~min}$. The product was successively distilled at atomospheric pressure.

$B-n(n=4-6)$ : IR $(\mathrm{KBr}): v 1641 \mathrm{~cm}^{-1}(\mathrm{C}=\mathrm{C})$.

4-Bromobutene (B-4): yield $85 \%$; bp $97^{\circ} \mathrm{C}$ (lit. $98-$ $\left.100^{\circ} \mathrm{C}\right) .{ }^{1} \mathrm{H} \mathrm{NMR}\left(\mathrm{CDCl}_{3}\right): \delta$ ppm $5.7(\mathrm{~m},=\mathrm{CH}-), 5.0$ $\left(\mathrm{q}, \mathrm{CH}_{2}=\right), 3.3\left(\mathrm{t},-\mathrm{CH}_{2}-\mathrm{Br}\right), 2.5\left(\mathrm{~m},-\mathrm{CH}_{2}-\right)$.

5-Bromopentene (B-5): yield $91 \%$; bp $117^{\circ} \mathrm{C}$ (lit. $\left.118-119^{\circ} \mathrm{C}\right) .{ }^{1} \mathrm{H} \mathrm{NMR}\left(\mathrm{CDCl}_{3}\right): \delta \mathrm{ppm} 5.5(\mathrm{~m},=\mathrm{CH}-)$, $4.8\left(\mathrm{q}, \mathrm{CH}_{2}=\right), 4.0\left(\mathrm{~m},-\mathrm{CH}_{2}-\mathrm{Br}\right), 1.6-2.2(\mathrm{~m}$, $\left.-\mathrm{CH}_{2}-\mathrm{CH}_{2}-\right)$.

6-Bromohexene (B-6): yield $84 \%$; bp $148^{\circ} \mathrm{C}$ (lit. $\left.147-150^{\circ} \mathrm{C}\right) .{ }^{1} \mathrm{H} \mathrm{NMR}\left(\mathrm{CDCl}_{3}\right): \delta \mathrm{ppm} 5.8(\mathrm{~m},=\mathrm{CH}-)$, $5.0\left(\mathrm{t}, \quad \mathrm{CH}_{2}=\right), \quad 3.4\left(\mathrm{t},-\mathrm{CH}_{2}-\mathrm{Br}\right), \quad 1.4-2.1 \quad(\mathrm{~m}$, $-\mathrm{CH}_{2}-\mathrm{CH}_{2}-\mathrm{CH}_{2}-$ ).

General Procedure for the Preparation of 4-( $\omega)-($ Alkenyloxy)benzoic Acid BA- $n(n=3-6)$

A mixture of B- $n$ ( $24 \mathrm{mmol}), p$-hydroxy benzoic acid $(20 \mathrm{mmol})$, and $18 \%$ aqueous potassium hydroxide ( 5 $\mathrm{mL})$ in ethanol $(80 \mathrm{~mL})$ was refluxed for $14 \mathrm{~h}$. Then, the mixture was neutralized with $25 \% \mathrm{HCl}$. The resolving mixture was poured into water. Recrystallization from water gave white plates.

BA- $n(n=3-6)$ : IR (KBr): $v 1169 \mathrm{~cm}^{-1}(\mathrm{C}-\mathrm{O}-\mathrm{C})$.

2-Propenyloxybenzoic acid (BA-3): yield 55\%; mp $163^{\circ} \mathrm{C} .{ }^{1} \mathrm{H} \mathrm{NMR}\left(\mathrm{CDCl}_{3}\right): \delta \mathrm{ppm} 6.9-8.0\left(\mathrm{q},-\mathrm{C}_{6} \mathrm{H}_{4}-\right)$, $6.0(\mathrm{~m},=\mathrm{CH}-), 5.3\left(\mathrm{q}, \mathrm{CH}_{2}=\right), 4.6\left(\mathrm{~d},-\mathrm{CH}_{2}-\mathrm{O}-\right)$.

$\begin{array}{llll}\mathrm{C}_{10} \mathrm{H}_{10} \mathrm{O}_{3} & & \mathrm{C} / \% & \mathrm{H} / \% \\ & \text { Calcd } & 67.41 & 5.66 \\ & \text { Found } & 67.28 & 5.53\end{array}$

3-Butenyloxybenzoic acid (BA-4): yield $54 \%$; mp $134^{\circ} \mathrm{C} .{ }^{1} \mathrm{H}$ NMR $\left(\mathrm{CDCl}_{3}\right): \delta$ ppm $6.9-8.0\left(\mathrm{q},-\mathrm{C}_{6} \mathrm{H}_{4}-\right)$, $5.8(\mathrm{~m},=\mathrm{CH}-), 5.1\left(\mathrm{t}, \mathrm{CH}_{2}=\right), 4.0\left(\mathrm{t},-\mathrm{CH}_{2}-\mathrm{O}-\right), 2.5$ (q, $-\mathrm{CH}_{2}-$ ).

$\begin{array}{lllc}\mathrm{C}_{11} \mathrm{H}_{12} \mathrm{O}_{3} & & \mathrm{C} / \% & \mathrm{H} / \% \\ & \text { Calcd } & 68.73 & 6.29 \\ & \text { Found } & 68.67 & 6.33\end{array}$

4-Pentenyloxybenzoic acid (BA-5): yield 75\%; mp $153^{\circ} \mathrm{C} .{ }^{1} \mathrm{H}$ NMR $\left(\mathrm{CDCl}_{3}\right): \delta$ ppm $6.9-8.0\left(\mathrm{q},-\mathrm{C}_{6} \mathrm{H}_{4}-\right)$, $5.8(\mathrm{~m},=\mathrm{CH}-), 5.0\left(\mathrm{t}, \mathrm{CH}_{2}=\right), 4.0\left(\mathrm{t},-\mathrm{CH}_{2}-\mathrm{O}\right), 1.8-2.3$ (m, $-\mathrm{CH}_{2}-\mathrm{CH}_{2}-$ ).

$\begin{array}{llll}\mathrm{C}_{12} \mathrm{H}_{14} \mathrm{O}_{3} & & \mathrm{C} / \% & \mathrm{H} / \% \\ & \text { Calcd } & 69.88 & 6.84 \\ & \text { Found } & 70.16 & 6.88\end{array}$

5-Hexenyloxybenzoic acid (BA-6): yield 89\%; mp $142^{\circ} \mathrm{C} .{ }^{1} \mathrm{H}$ NMR $\left(\mathrm{CDCl}_{3}\right): \delta \mathrm{ppm} 6.9-8.0\left(\mathrm{q},-\mathrm{C}_{6} \mathrm{H}_{4}-\right)$, $5.8(\mathrm{~m},=\mathrm{CH}-), 5.0\left(\mathrm{t}, \mathrm{CH}_{2}=\right), 4.0\left(\mathrm{t},-\mathrm{CH}_{2}-\mathrm{O}-\right)$, $1.2-2.1\left(\mathrm{~m},-\mathrm{CH}_{2}-\mathrm{CH}_{2}-\mathrm{CH}_{2}-\right)$.

$\begin{array}{llcc}\mathrm{C}_{13} \mathrm{H}_{16} \mathrm{O}_{3} & & \mathrm{C} / \% & \mathrm{H} / \% \\ & \text { Calcd } & 70.89 & 7.32 \\ & \text { Found } & 71.08 & 7.37\end{array}$

General Procedure for the Preparation of 4-Acetoylphenyl 4-( $\omega$-Alkenyloxy)benzoate APB- $n(n=3-6)$

A mixture of BA- $n$ (1 mmol), 4'-hydroxyacetophenone (1.2 mmol), $N, N^{\prime}$-dicyclohexylcarbodiimide (DCC) $(1.2$ mmol), triethylamine (TEA) (several drops), and potassium carbonate $(33 \mathrm{mmol})$ in methylene chloride $(50 \mathrm{~mL})$ was refluxed for $24 \mathrm{~h}$. The insoluble precipitate was separated by filtration and the filtrate was concentrated to dryness. After removing the methylene chloride under reduced pressure, the residue was extracted with $50 \mathrm{~mL}$ portions of ether. The combined extract was washed with water and dried over magnesium sulfate. Filtration and removal of solvent gave solids. Recrystallization from methanol gave white needles.

APB- $n(n=3-6)$ : IR (KBr): $v 1728 \mathrm{~cm}^{-1}$ (-COO-).

4-Acetoylphenyl 4-(3-propenyloxy)benzoate (APB-3): yield $70 \% ; \mathrm{mp} 120{ }^{\circ} \mathrm{C} .{ }^{1} \mathrm{H} \mathrm{NMR}\left(\mathrm{CDCl}_{3}\right): \delta \mathrm{ppm} 6.9-8.0$ $\left(\mathrm{m}, 2-\mathrm{C}_{6} \mathrm{H}_{4}-\right), 6.0(\mathrm{~m},=\mathrm{CH}-), 5.4\left(\mathrm{q}, \mathrm{CH}_{2}=\right), 4.6(\mathrm{~d}$, $\left.-\mathrm{CH}_{2}-\mathrm{O}-\right), 2.6$ (s, $\mathrm{CO}-\mathrm{CH}_{3}$ ).

$\begin{array}{llll}\mathrm{C}_{18} \mathrm{H}_{16} \mathrm{O}_{4} & & \mathrm{C} / \% & \mathrm{H} / \% \\ & \text { Calcd } & 72.95 & 5.45 \\ & \text { Found } & 72.94 & 5.41\end{array}$

4-Acetoylphenyl 4-(4-butenyloxy)benzoate (APB-4): 
yield $31 \%$; mp $97^{\circ} \mathrm{C} .{ }^{1} \mathrm{H}$ NMR $\left(\mathrm{CDCl}_{3}\right): \delta$ ppm 6.9-8.0 $\left(\mathrm{m}, 2-\mathrm{C}_{6} \mathrm{H}_{4}-\right), 5.8(\mathrm{~m},=\mathrm{CH}-), 5.1\left(\mathrm{t}, \mathrm{CH}_{2}=\right), 4.1(\mathrm{t}$, $\left.-\mathrm{CH}_{2}-\mathrm{O}-\right), 2.6$ (s, $\left.\mathrm{CO}-\mathrm{CH}_{3}\right), 2.5\left(\mathrm{q},-\mathrm{CH}_{2}-\right.$ ).

$\begin{array}{cccc}\mathrm{C}_{19} \mathrm{H}_{18} \mathrm{O}_{4} & & \mathrm{C} / \% & \mathrm{H} / \% \\ & \text { Calcd } & 73.53 & 5.85 \\ & \text { Found } & 73.59 & 6.07\end{array}$

4-Acetoylphenyl 4-(5-octenyloxy)benzoate (APB-5): yield $57 \%$; mp $98^{\circ} \mathrm{C} .{ }^{1} \mathrm{H}$ NMR $\left(\mathrm{CDCl}_{3}\right): \delta$ ppm $6.9-8.0$ $\left(\mathrm{q},-\mathrm{C}_{6} \mathrm{H}_{4}-\right), 5.8(\mathrm{~m},=\mathrm{CH}-), 5.0\left(\mathrm{t}, \mathrm{CH}_{2}=\right), 4.0(\mathrm{t}$, $\left.-\mathrm{CH}_{2}-\mathrm{Br}\right), 2.6\left(\mathrm{~s}, \mathrm{CO}-\mathrm{CH}_{3}\right) 1.8-2.3\left(\mathrm{~m},-\mathrm{CH}_{2}-\mathrm{CH}_{2}-\right)$.

$\begin{array}{cccc}\mathrm{C}_{20} \mathrm{H}_{20} \mathrm{O}_{4} & & \mathrm{C} / \% & \mathrm{H} / \% \\ & \text { Calcd } & 74.05 & 6.22 \\ & \text { Found } & 74.14 & 6.27\end{array}$

4-Acetoylphenyl 4-(6-hexenyloxy)benzoate (APB-6): yield $54 \%$; mp $82{ }^{\circ} \mathrm{C}$. ${ }^{1} \mathrm{H}$ NMR $\left(\mathrm{CDCl}_{3}\right): \delta$ ppm 6.9-8.0 $\left(\mathrm{q},-\mathrm{C}_{6} \mathrm{H}_{4}-\right), 5.8(\mathrm{~m},=\mathrm{CH}-), 5.0\left(\mathrm{t}, \mathrm{CH}_{2}=\right), 4.0(\mathrm{t}$, $\left.-\mathrm{CH}_{2}-\mathrm{O}-\right), 2.6\left(\mathrm{~s}, \mathrm{CO}-\mathrm{CH}_{3}\right), 1.2-2.1\left(\mathrm{~m},-\mathrm{CH}_{2}-\mathrm{CH}_{2}-\right.$ $\mathrm{CH}_{2}-$ ).

$\begin{array}{llcc}\mathrm{C}_{21} \mathrm{H}_{22} \mathrm{O}_{4} & & \mathrm{C} / \% & \mathrm{H} / \% \\ & \text { Calcd } & 74.54 & 6.55 \\ & \text { Found } & 74.72 & 6.66\end{array}$

Liquid Crystalline Polysiloxane PAMS- $n(n=3-6)$

A typical example of the hydrosilylation is as follows. In a $25 \mathrm{~mL}$ two-necked round bottomed flask were placed polydrogenmethylsiloxane $(0.1 \mathrm{~g}, 1.8 \mathrm{mmol})$ and APB- $n$ $(2 \mathrm{mmol})$ in toluene $(50 \mathrm{~mL})$. Then, platinum catalyst $(20 \mu \mathrm{L})$ in isopropanol was added via syringe through the serum cap. The reaction mixture was heated at $100^{\circ} \mathrm{C}$ for $24 \mathrm{~h}$. The extent of the reaction was monitored by the disappearance of absorption of silyl hydride at $2160 \mathrm{~cm}^{-1}$ in the IR spectrum. After removal of the solvent, the residue was dissolved in methylene chloride. This solution was poured into methanol. Polymer purification was done by repeated precipitation form methylene chloride with methanol. The product was filtered and dried.

PCMS- $n$ ( $n=3-6)$ : IR (film): $v \mathrm{~cm}^{-1} 761\left(\mathrm{Si}-\mathrm{CH}_{2}\right)$.

Poly $[\{3-\{4-(4-($ acetoyl)phenoxy carbonyl)phenoxy $\}\}-$ propyl methyl siloxane] (PAMS-3): yield 36\%. ${ }^{1} \mathrm{H}$ NMR $\left(\mathrm{CDCl}_{3}\right): \delta$ ppm 6.7-8.0 (b, 2- $\left.\mathrm{C}_{6} \mathrm{H}_{4}-\right), 3.8\left(\mathrm{~b},-\mathrm{CH}_{2}-\mathrm{O}-\right)$, $2.5\left(\mathrm{~b}, \mathrm{CO}-\mathrm{CH}_{3}\right), 1.8\left(\mathrm{~b},-\mathrm{CH}_{2}-\right), 0.7$ (b, Si-CH$\left.{ }_{2}^{-}\right)$.

Poly[4-\{4-(4-(acetoyl)phenoxy carbonyl)phenoxy $\}\}-$ butyl methyl siloxane] (PAMS-4): yield 19\%. ${ }^{1} \mathrm{H}$ NMR $\left(\mathrm{CDCl}_{3}\right): \delta$ ppm 6.8-8.1 (b, 2- $\left.\mathrm{C}_{6} \mathrm{H}_{4}-\right), 3.9\left(\mathrm{~b},-\mathrm{CH}_{2}-\mathrm{O}-\right)$, $2.6\left(\mathrm{~b}, \mathrm{CO}-\mathrm{CH}_{3}\right), 1.5-1.8\left(\mathrm{~b},-\mathrm{CH}_{2}-\mathrm{CH}_{2}-\right), 0.6(\mathrm{~b}$, $\mathrm{Si}-\mathrm{CH}_{2}-$ ).
Poly[5-\{4-(4-(acetoyl)phenoxy carbonyl)phenoxy\}\}pentyl methyl siloxane] (PAMS-5): yield 47\%. ${ }^{1} \mathrm{H}$ NMR $\left(\mathrm{CDCl}_{3}\right): \delta$ ppm 6.9-8.1 (b, 2- $\left.\mathrm{C}_{6} \mathrm{H}_{4}-\right), 3.9\left(\mathrm{~b},-\mathrm{CH}_{2}-\mathrm{O}-\right)$, 2.5 (b, $\left.\mathrm{CO}-\mathrm{CH}_{3}\right), 1.5-1.8\left(\mathrm{~b},-\mathrm{CH}_{2}-\mathrm{CH}_{2}-\mathrm{CH}_{2}-\right), 0.6$ (b, $\mathrm{Si}-\mathrm{CH}_{2}-$ ).

Poly[6-\{4-(4-(acetoyl)phenoxy carbonyl)phenoxy $\}\}-$ hexyl methyl siloxane] (PAMS-6): yield 55\%. ${ }^{1} \mathrm{H}$ NMR $\left(\mathrm{CDCl}_{3}\right): \delta \mathrm{ppm} 6.9-8.0\left(\mathrm{~b}, 2-\mathrm{C}_{6} \mathrm{H}_{4}-\right), 3.9\left(\mathrm{~b},-\mathrm{CH}_{2}-\mathrm{O}-\right)$, $2.5\left(\mathrm{~b}, \mathrm{CO}-\mathrm{CH}_{3}\right), 1.2-1.8\left(\mathrm{~b},-\mathrm{CH}_{2}-\mathrm{CH}_{2}-\mathrm{CH}_{2}-\mathrm{CH}_{2}-\right)$, $0.6\left(\mathrm{~b}, \mathrm{Si}-\mathrm{CH}_{2}-\right)$.

Acknowledgment. We are indebted to Prof. Mitsuru Ueda of Yamagata University for his helpful discussions on the synthesis.

\section{REFERENCES}

1. H. Finkelmann, M. Happ, M. Portugal, and H. Ringsdorf, Makromol. Chem., 179, 2541 (1978).

2. G. Rehage and H. Finkelmann, Adv. Polym. Sci., 60/61, 99 (1984).

3. N. A. Plate and V. P. Shibaev, "Comb-Shaped Polymers and Liquid Crystals," Plenum Press, New York, N.Y., 1987.

4. D. J. Simmonds, in "Liquid Crystal Polymers," A. A. Collyer, Ed., Elsevier Applied Science, London, 1992, pp 349-406.

5. V. Shibaev, Mol. Crys. Liq. Crys., 243, 201 (1994).

6. H. Finkelmann and G. Rehage, Makromol. Chem. Rapid Commun., 1, 31 (1980).

7. H. Finkelmann, H.-J. Kock, and G. Rehage, Makromol. Chem., Rapid Commun., 2, 317 (1981).

8. H. Stevens, G. Rehage, and H. Finkelmann, Macromolecules, 17, 851 (1984).

9. G. Nestor, M. S. White, G. W. Grey, D. Lacey, and K. J. Toyne, Makromol. Chem., 188, 2759 (1987).

10. Y. S. Freidzon, R. V. Talrose, N. I. Boko, S. G. Kostromin, V. P. Shibaev, and N. A. Plate, Liq. Cryst., 3,'127 (1988).

11. P. A. Gemmell, G. W. Gray, and D. Lacey, Mol. Cryst. Liq. Cryst., 122, 205 (1985).

12. V. P. Shibaev, S. G. Kostromin, and N. A. Plate, Eur. Polym. $J ., 18,651$ (1982).

13. S. G. Kostromin, V. V. Sinitzyn, R. V. Talrose, V. P. Shibaev, and N. A. Plate, Makromol. Chem., Rapid Commun., 3, 809 (1982).

14. S. G. Kostromin, V. V. Sinitzyn, R. V. Tal'rose, and V. P. Shibaev, Polym. Sci. U.S.S.R., 26, 370 (1984).

15. V. P. Shibaev and N. A. Plate, Pure Appl. Chem., 57, 1589 (1985).

16. G. W. Gray, D. Lacey, G. Nestor, and M. S. White, Makromol. Chem. Rapid. Commun., 7, 71 (1986).

17. M. Yamada, T. Iguchi, A. Hirao, S. Nakahama, and J. Watanabe, Macromolecules, 28, 50 (1995).

18. K. Yonetake, M. Nakagomi, and T. Masuko, Polym. J., 27, 1157 (1995).

19. K. Yonetake, M. Nakagomi, M. Ueda, and T. Masuko, Polym. J., 29, 240 (1997). 